\title{
Comparison of K-Sol and M-K medium for cornea storage: results of penetrating keratoplasty in rabbits
}

\author{
MASSIMO BUSIN, CHI-WANG YAU, ISAAC AVNI, \\ AND HERBERT E KAUFMAN \\ From the Lions Eye Research Laboratories, LSU Eye Center, Louisiana State University Medical Center \\ School of Medicine, New Orleans, Louisiana, USA
}

SUMMARY Five pairs of rabbit corneas were stored for two weeks at $4^{\circ} \mathrm{C}$, one of each pair in K-Sol medium, and one in McCarey-/Kaufman (M-K) medium. After transplantation all penetrating keratoplasty grafts became clear and thin. Endothelial cell loss was significantly less in the K-Sol stored corneas. Another five pairs of corneas were stored for two weeks in K-Sol or three days in M-K medium. After penetrating keratoplasty there were no significant differences in clarity, thickness, or endothelial cell loss. The results indicate that $\mathrm{K}$-Sol provides satisfactory mediumterm corneal storage compared with short-term storage in $\mathrm{M}-\mathrm{K}$ medium at refrigerator temperatures.

K-Sol, a new corneal preserving medium, which contains TC-199, 2.5\% chondroitin sulphate, and HEPES buffer, has been tested for medium-term storage of donor corneas for two weeks with satisfactory results. ${ }^{2}$ The present study was designed to compare K-Sol and M-K medium preservation of endothelial cell viability in rabbit corneas after penetrating keratoplasty.

\section{Materials and methods}

TWO-WEEK STORAGE IN K-SOL AND M-K MEDIUM

Animal care and treatment in this investigation were in compliance with the ARVO resolution on the use of animals in research. Five New Zealand white rabbits, 2-3 $\mathrm{kg}$ body weight, were killed with an overdose of intracardiac pentobarbital. Paired corneas with $2 \mathrm{~mm}$ of scleral rim were excised by means of standard eye bank procedures. Endothelial cell density was determined by specular microscopy. One cornea from each rabbit was stored in K-Sol (Cilco), and the fellow cornea was stored in M-K medium, both at $4^{\circ} \mathrm{C}$. Gentamicin $(100 \mu \mathrm{g} / \mathrm{ml}(100$ $\mathrm{mg} / \mathrm{l})$ was added to both preserving solutions. After two weeks the paired corneas were used for penetrat-

Correspondence to Herbert E Kaufman, MD, LSU Eye Center, 2020 Gravier St, Suitc B, New Orlcans, Louisiana 70112, USA. ing keratoplasty. A $7.5 \mathrm{~mm}$ donor button was trephined from the endothelial side, and the graft was transplanted into a $7 \cdot 0 \mathrm{~mm}$ recipient bed and sutured with 10-0 nylon. One eye of each of five rabbits received a cornea stored in $\mathrm{K}$-Sol and the fellow eye received the mate cornea, stored in $\mathrm{M}-\mathrm{K}$ medium. After surgery $1 \%$ atropine and gentamicin ointment were applied daily for three days.

Postoperative examinations included slit-lamp biomicroscopy to evaluate graft clarity and the measurement of central graft thickness by ultrasonic pachymetry (Acutome corneometer; $1640 \mathrm{~m} / \mathrm{s}$ ) on days $1,3,5,7$, and 14 . On day 14 the rabbits were killed by an overdose of pentobarbital and the corneas obtained and stored in the original preserving medium until the cells were counted. Endothelial cell density was determined by three independent observers, each of whom counted cell densities in three different $1 \mathrm{~mm}^{2}$ areas. All examinations, as well as the surgery, were performed in a masked fashion.

TWO-WEEK STORAGE IN K-SOL, THREE-DAY STORAGE IN M-K MEDIUM

Paired corneas from five rabbits were used. One cornea from each pair was stored in K-Sol for two weeks and the fellow cornea was stored in $M-K$ medium for three days, both at $4^{\circ} \mathrm{C}$. The surgical procedure and postoperative examinations were identical to those described above. 
Results

TWO-WEEK STORAGE IN K-SOL AND M-K MEDIUM

Both groups of grafts were oedematous on the first postoperative day: $0.565 \pm 0.08 \mathrm{~mm}$ for those stored in $\mathrm{K}-\mathrm{Sol}$, and $0.587 \pm 0.06 \mathrm{~mm}$ for those stored in M-K medium $( \pm$ here and below denotes standard error of the mean). Swelling decreased rapidly. By day 3 corneal thickness was $0 \cdot 400 \pm 0.03 \mathrm{~mm}$ in the K-Sol group and $0.410 \pm 0.04 \mathrm{~mm}$ in the M-K group (Fig. 1). All the grafts continued to decrease in thickness thereafter, but differences between the two groups were not statistically significant at any time.

All but one of the grafts were clear after day 5 . One rabbit with a graft stored in K-Sol had broken sutures over one quadrant and the anterior chamber was filled with fibrin clots on day 7. During an attempt to remove the fibrin clots and repair the wound the lens was ruptured, with vitreous prolapse. The lens material was removed and anterior vitrectomy performed, after which the wound was repaired successfully. On day 14 the graft was still oedematous, with a corneal thickness of $0.51 \mathrm{~mm}$; the graft in the fellow eye remained clear. The graft in the damaged eye cleared on day 21 , at which time cell densities were determined in both eyes of this rabbit. Endothelial

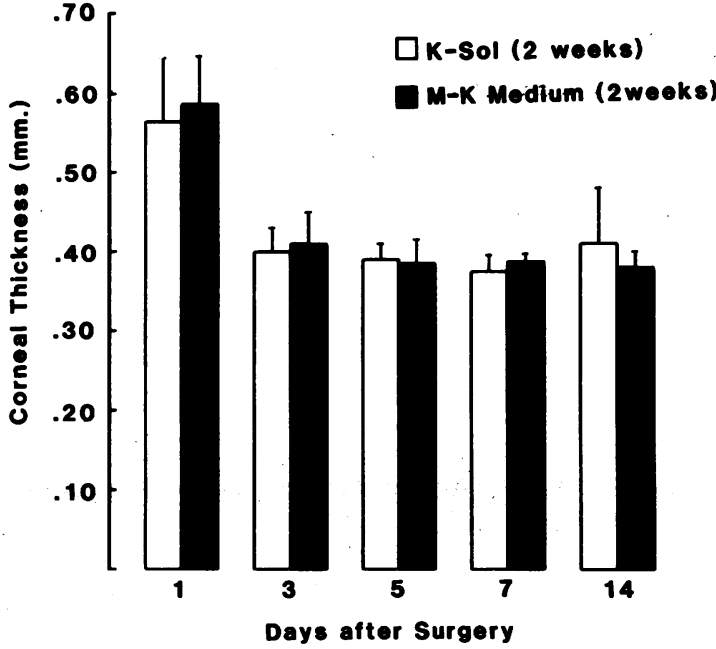

Fig. 1 Change of central corneal thickness after surgery. $T$ wo weeks storage in $K$-Sol and $M-K$ medium. One cornea of this group needed resuturing on the eighth postoperative day.

cell density was higher in the K-Sol stored eye than in the fellow eye with the M-K medium-stored donor tissue (Fig. 2).

Endothelial cell loss averaged $24 \cdot 2 \%$ in the K-Sol
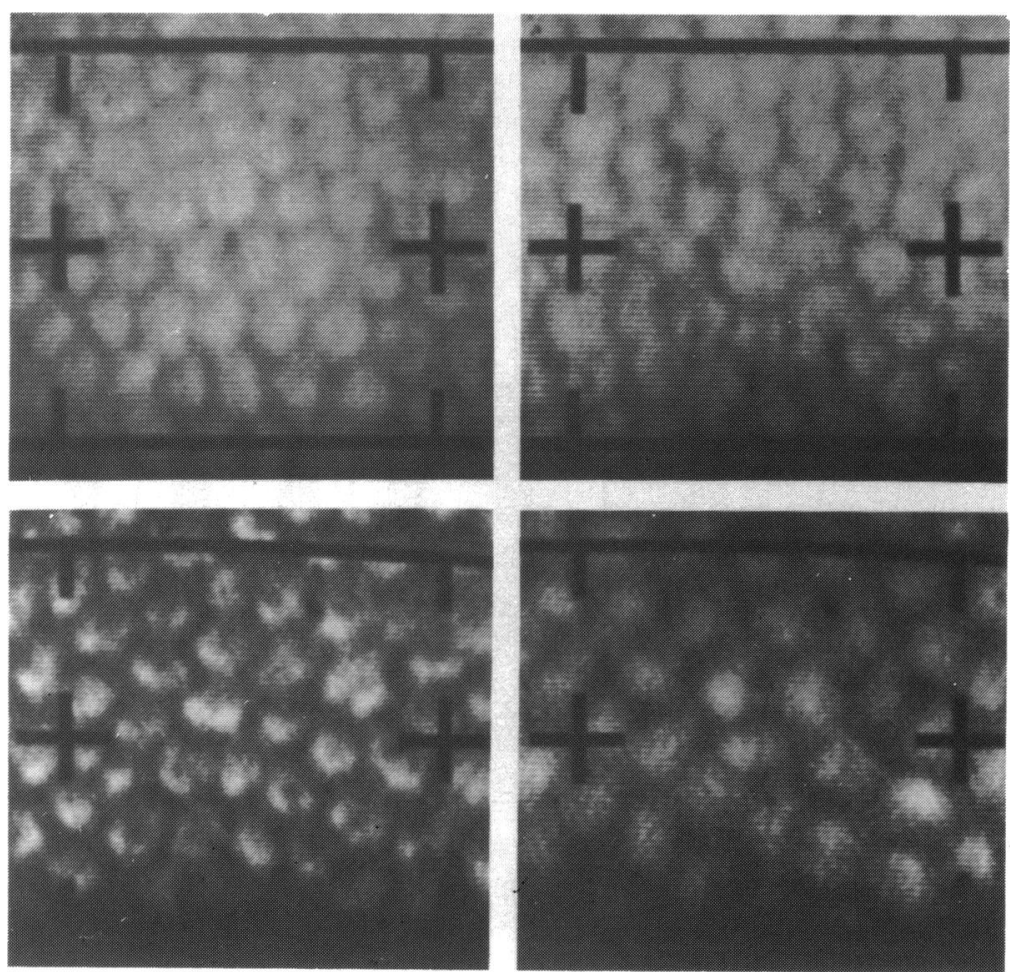

Fig. 2 Specular microscopy of endothelial cells preoperatively and three weeks after surgery. Right: Cornea stored in $\mathrm{K}$-Sol for two weeks. Repair of wound dehiscence after lens extraction and anterior vitrectomy. Cell density before surgery $=3900 / \mathrm{mm}^{2}$ (above), after surgery $=3000 / \mathrm{mm}^{2}$ (below). Cell loss $=23 \%$. Left: Fellow cornea stored in $M-K$ medium for two weeks. Cell density before surgery= $3800 / \mathrm{mm}^{2}$ (above), after surgery = $2400 / \mathrm{mm}^{2}$ (below). Cell loss $=$ $36 \cdot 8 \%$. 
Table 1 Endothelial cell density $\left(\right.$ cell/ $\left.\mathrm{mm}^{2}\right)$ before and after surgery. Donor corneas stored for two weeks

\begin{tabular}{|c|c|c|c|c|c|c|}
\hline \multirow[b]{2}{*}{ Rabbit no. } & \multicolumn{2}{|c|}{ Storage in K-Sol (14 days) } & \multirow[b]{2}{*}{$\%$ Cell loss } & \multicolumn{3}{|c|}{ Storage in $M-K$ medium ( 14 days) } \\
\hline & Before surgery & After surgery & & Before surgery & After surgery & $\%$ Cell loss \\
\hline 4135 & 3400 & $24(0)$ & $29 \cdot 4$ & 3300 & 2100 & $36 \cdot 3$ \\
\hline 4029 & 3300 & 2400 & $27 \cdot 3$ & 3300 & 2100 & $36 \cdot 3$ \\
\hline 4124 & 3900 & 3000 & $23 \cdot 1$ & 3800 & 2400 & $36 \cdot 8$ \\
\hline 4138 & $32(x)$ & $27(x)$ & $15 \cdot 6$ & 3300 & 2300 & $30 \cdot 3$ \\
\hline 4119 & 3500 & 2600 & $25 \cdot 7$ & 3700 & 2800 & $26 \cdot 4$ \\
\hline
\end{tabular}

Cell loss in M-K stored corneas significantly higher than in K-Sol stored corneas $(\mathrm{p}=(\mathbf{0} \cdot(\mathbf{0 2 3})$. Paired Student's $t$ test .

Table 2 Endothelial cell density (cell/ $\mathrm{mm}^{2}$ ) before and after surgery. Donor corneas stored in K-Sol for two weeks or in $M-K$ medium for three days

\begin{tabular}{|c|c|c|c|c|c|c|}
\hline \multirow[b]{2}{*}{ Rabbit no. } & \multicolumn{3}{|c|}{ Storage in K-Sol (14 days) } & \multicolumn{3}{|c|}{ Storage in $M-K$ medium ( 3 days) } \\
\hline & Before surgery & After surgery & $\%$ Cell loss & Before surgery & After surgery & $\%$ Cell loss \\
\hline 4118 & 3200 & 2600 & $18 \cdot 7$ & 3500 & 2500 & $28 \cdot 5$ \\
\hline 4128 & $37(x)$ & 3100 & $13 \cdot 5$ & 3800 & 2800 & $26 \cdot 3$ \\
\hline 4127 & $37(00$ & 2400 & $35 \cdot 1$ & 3600 & 2700 & $25 \cdot 0$ \\
\hline 4145 & 3300 & 3100 & $6 \cdot 1$ & 3300 & 2900 & $12 \cdot 1$ \\
\hline 4122 & 3300 & 2500 & $24 \cdot 2$ & 3300 & 2200 & $33 \cdot 3$ \\
\hline
\end{tabular}

Cell loss not significantly different in the two groups. Paired Student's $t$ test.

group and $33.2 \%$ in the $\mathrm{M}-\mathrm{K}$ medium group (Table $1)$. The difference was statistically significant $(p=$ $0 \cdot 023)$.

TWO-WEEK STORAGE IN K-SOL, THREE-DAY STORAGE IN M-K MEDIUM

On the first postoperative day all grafts were oedematous; the K-Sol group was slightly thicker than the M$\mathrm{K}$ medium group (Fig. 3). Both groups of grafts thinned rapidly, and all grafts were clear and less than $0.4 \mathrm{~mm}$ in thickness on day five. Differences in thickness between the two groups were not significant.

Endothelial cell loss in four of the five K-Sol stored grafts was slightly less than the M-K stored grafts but the differences were not statistically significant (Table 2, Fig. 4).

\section{Discussion}

M-K medium, which contains TC-199, HEPES buffer, and dextran, has been widely used to preserve donor corneal tissue in eye banks all over the United States. However, M-K medium is a short-term storage solution, with a maximum preservation time of 72 hours depending on the condition of the donor tissue prior to storage. ${ }^{3+}$ Prolonged preservation in this medium is not recommended. Early studies by Van Horn et al. showed more than $20 \%$ cell death in cat corneas after five days of storage in $\mathrm{M}-\mathrm{K}$ medium.

K-Sol contains TC-199, HEPES buffer, and chondroitin sulphate. In studies comparing chondroitin sulphate and dextran in preservative media Schimmelpfennig found that $5 \%$ chondroitin sulphate reduced endothelial cell damage in human eyes, compared with $5 \%$ dextran, after one or two weeks of

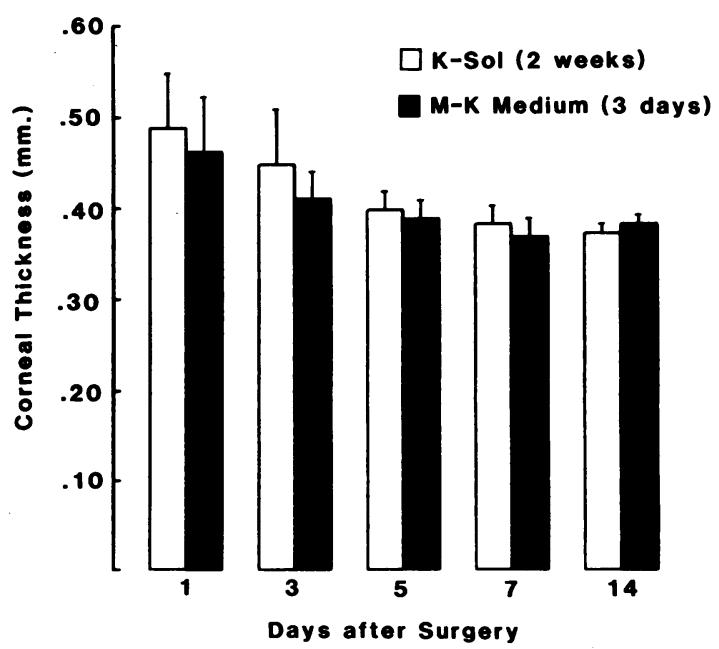

Fig. 3 Change in corneal thickness after surgery. Corneas were stored in $K$-Sol for two weeks or $M-K$ medium for three days. 

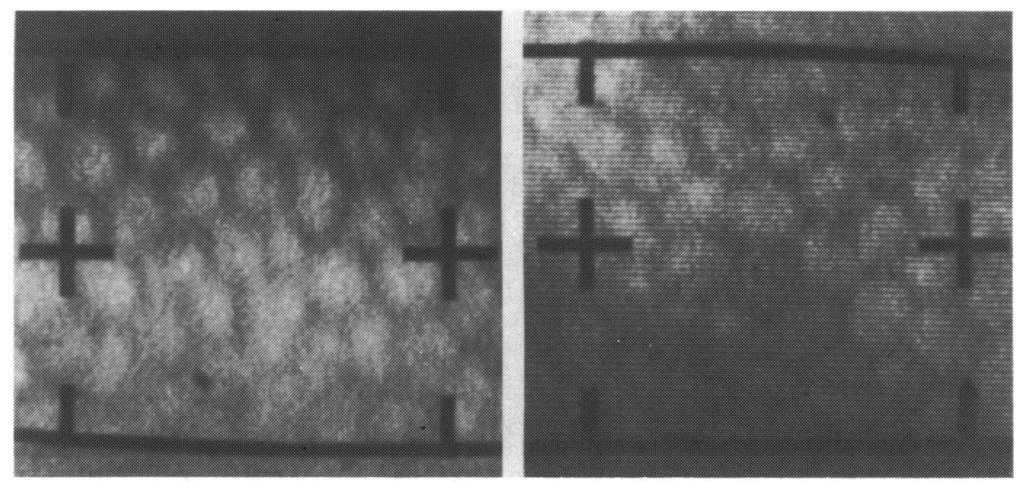

Fig. 4 Specular microscopy of endothelial cells two weeks after surgery. Preoperative cell density in both corneas $=3300 / \mathrm{mm}^{2}$. Right: Cornea stored in $K-S o l$ for $1 w 0$ weeks. Cell density after surgery = $3100 / \mathrm{mm}^{2}$. Cell loss $=6 \cdot 1 \%$. Left: Fellow cornea stored in $M-K$ medium for three days. Cell density after surgery $=2900 / \mathrm{mm}^{2}$. Cell loss $=12 \cdot 1 \%$.

storage. "Stein et al. also found that $1.5 \%$ chondroitin sulphate gave excellent endothelial preservation for two weeks.? In our previous studies we found that $2 \cdot 5 \%$ chondroitin sulphate is the optimal concentration for corneal storage.' The osmolality of K-Sol is $310 \mathrm{mOsm}$, and the $\mathrm{pH}$ is maintained at 7.4 by HEPES buffer, which has also been determined to be optimal for corneal preservation. ${ }^{.4}$

In the present study two weeks of storage in K-Sol and $\mathrm{M}-\mathrm{K}$ medium followed by penetrating keratoplasty demonstrated no differences in corneal deturgescence and graft clarity, but significantly less endothelial cell loss in the K-Sol group. In their study of penetrating keratoplasty in rabbits Bigar et al. ${ }^{11}$ obtained clear grafts from donor corneas stored in $\mathrm{M}-\mathrm{K}$ medium up to 14 days. In our study, after 14 days of storage in M-K medium, all grafts were also clear, and the average endothelial cell density was still adequate to maintain healthy corneas ( 2225 cells/ $\mathrm{mm}^{2}$ ). However, our quantitation of endothelial cell loss in the early postoperative period indicates that K-Sol provided better preservation of endothelial cells than M-K medium over a two-week period, and at least comparable preservation for 14 days compared with three-day M-K storage.

In spite of the fact that rabbit corneal endothelium is capable of cell division and regeneration it is important to note that, in this study, even 14 days after surgery there was still a significant difference in endothelial cell densities in the groups that received corneas stored for two weeks in the two media. It seems probable that this difference can be attributed to improved preservation of the endothelial cells stored in K-Sol compared with those stored in M-K medium for this medium-term interval. The fact that the K-Sol stored graft with the broken suture sur- vived with less cell loss than the fellow eye implies that corneas stored in K-Sol for two weeks can tolerate severe surgery with no long-lasting ill effects. Further investigation in humans is needed to confirm these findings.

Supported in part by PHS grants EY02580 and EY(02377 from the National Eye Institute, National Institutes of Health. Bethesda. Maryland.

\section{References}

1 Kaufman HE, Varnell ED, and Kaufman S. Chondroitin sulfate in a new cornea preservation medium. Am J Ophthalmol 1984: 98: $112-4$.

2 Kaufman HE, Varnell ED, Kaufman S, Beuerman RW, Barron BA. K-Sol corneal preservation. Am J Ophthalmol 1985; 100: 299-304.

3 McCarey BE, and Kaufman HE. Improved corneal storage. Invest Ophthalmol Vis Sci 1974; 13: 165-73.

4 McCarey BE, Meyer RF, and Kaufman HE. Improved corncal storage for penetrating keratoplasty in humans. Ann Ophthalmol 1976:8: $1488-95$.

5 Van Horn DL, Schultz RO, DeBruin J. Endothelial survival in corneal tissue stored in M-K medium. Am J Ophthalmol 1975; 80: 642 .

6 Schimmelpfennig B. Endothelial damage at $4^{\circ} \mathrm{C}$ in dextran and chondroitin sulfate containing storage media. Invest Ophthalmol Vis Sci 1985; 20(suppl): 238 (ARVO abstract).

7 Stein RM, Bourne WM, Campbell RJ. Comparison of $1.5 \%$ chondroitin sulfate and $5 \%$ dextran for corneal storage. Invest Ophthalmol Vis Sci 1985; 20(suppl): 238 (ARVO abstract).

8 Edelhauser HF, Hannenken AM, Pederson HJ, Van Horn DL. Osmotic tolerance of rabbit and human corneal endothelium. Arch Ophthalmol 1981; 99: 1281-7.

9 Gonnering R, Edelhauser HF, Van Horn DL, Durant W. The $\mathrm{pH}$ tolerance of rabbit and human corncal endothelium. Invest Ophthalmol Vis Sci 1979; 18: 373-90.

10 Bigar F. McCarey BE, and Kaufman HE. Improved corneal storage: penetrating keratoplasty in rabbits. Exp Eye Res 1975 ; 20: $219-22$

Accepted for publication II February 1986. 